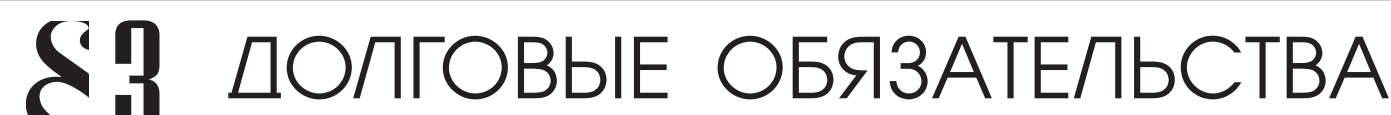 ГOCУ $\triangle A P C T B A$ (МУНИЦИПАЛЬНОГО ОБРАЗОВАНИЯ)
}

Чернобровкина Е. Б.

\section{ВЛИЯНИЕ БЮДЖЕТНОЙ ПОЛИТИКИ ГОСУДАРСТВА НА ПРАВОВОЕ РЕГУЛИРОВАНИЕ ПУБЛИЧНОГО ДОЛГА}

\begin{abstract}
Аннотация. Все современные государства, независимо от уровня их экономического развития, активно используют долговые долговые инструменты в иелях сбалансированности бюджетно-финансовой и денежно-кредитной политики. Современная российская экономика характеризуется тем, что представляет собой смешанную экономику, где рыночные инструменты дополняются государственным регулированием, финансовой базой которого является бюджет. Государственные заимствования являются важнейшим инструментом экономической политики государства, формирующим государственный долг. В современный период ни у кого не вызывает сомнений, что государственный долг должен быть управляем и контролируем. Сложившая система, хотя в целом и выполняет возложенные на нее цели и задачи, однако не лишена недостатков, как в экономическом, так и в правовом аспектах. Политические, социильно-экономические чели и задачи, которые стоят перед государством в данной области сформулированы и совершенно ясны. Но достаточно сложно подвести под них теоретическое правовое обоснование, облечь в правовую форму. В связи с чем, несмотря на огромную значимость для России правовые вопросы в данной сфере остаются недостаточно разработанными. Особенно это касается общественных отношений в сфере финансовоправового регулирования. Необходимость рассмотрения основных аспектов регулирования внешних заимствований обусловлена тем, что именно финансовое право устанавливает основы построения системы уполномоченных органов власти и организаций в данной сфере, их компетенцию, принцииы взаимоотношений друг с другом, а также форму и структуру заимствований. В основе научного подхода к исследуемой теме в юридических науках, в том числе финансово правовой науке, лежат четыре метода познания к ним относятся: формально-догматический, или специально-юридический, сравнительно-исторический метод исследования, метод сравнительно-правового исследования и метод конкретно-соииологического исследования. Значительное обновление российского финансового законодательства в том числе Бюджетного кодекса Российской Федераџии, сделало необходимьм глубокое и тщщательное изучение вопросов регулирования государственного долга в аспекте современных условий, так как новые правовые положения не столько решили, сколько поставили
\end{abstract}


много новых вопросов, подлежащих обстоятельному исследованию. Поэтому исследование финансово-правовой сущности управления государственным долгом актуально не только в целях рассмотрения уже существующих правовых коллизий, но имеет важное значение для развития конщепџии управления государственным долгом Российской Федерации в цฺелом. Политика заимствований и управления государственным долгом создает основы для решения стратегических и тактических задач сочиально экономического развития и выступает составной частью системы управления финансовыми ресурсами Российской Федерации. Эффективность финансовой системы государства находится в прямой зависимости от эффективности системы управления долговыми обязательствами.

Ключевые слова: бюджетная политика, государственный долг, внешний долг, внутренний долг, заимствования, программно-целевойметод, сбалансированность бюджета, дефицит, профицит, долговые требования.

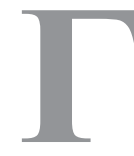

осударственный долг играет существенную и многогранную роль в макроэкономической системе любого государства. Это объясняется тем, что отношения по поводу формирования, обслуживания и погашения государственного долга оказывают значительное влияние на состояние публичных финансов, денежного обращения, инвестиционного климата, структуру потребления и развития международного сотрудничества государств.

Государственные заимствования позволяют решать проблемы нехватки средств при решении текущих задач исполнения бюджета и создают основу для перспективного развития, предоставляя возможности привлечения средств для достижения долгосрочных целей с учетом приоритетов инвестиционного развития.

Федеральным законом от 26 апреля 2007 года № 63-Ф3 «О внесении изменений в Бюджетный кодекс Российской Федерации и приведении в соответствие с бюджетным законодательством Российской Федерации отдельных законодательных актов Российской Федерации» ${ }^{1}$ в БК РФ были внесены значительные изменения, которые затронули сам бюджетный процесс, и другие бюджетные правоотношения, в том числе сложные и комплексные отношения, которые возни-

\footnotetext{
${ }^{1}$ С3 РФ.2007.№ 18.СТ. 2117.
}

кают при осуществлении РФ, субъектами РФ и муниципальными образованиями государственных и или муниципальных заимствований.

Изменения внесенные законом от 26.04. 2007 г. № 63-Ф3 затрагивающие правовое регулирование государственного (муниципального) долга, начинаются со ст. 6 БК РФ, в которой было дано новое определение таких понятий, как внешний долг и внутренний долг:

внешний долг - обязательства, возникающие в иностранной валюте, за исключением обязательств субъектов РФ и муниципальных образований перед РФ, возникающих в иностранной валюте в рамках использований целевых иностранных кредитов (заимствований);

внутренний долг - обязательства, возникающие в валюте РФ, а также обязательства субъектов РФ и муниципальных образований перед РФ, возникающих в иностранной валюте в рамках использований целевых иностранных кредитов (заимствований) .

Таким образом, с 1 января 2008 года из состава внешнего долга субъектов РФ и муниципальных образований был выведен долг в иностранной валюте, возникающий в рамках использования целевых иностранных кредитов (заимствований).

Предыдушая редакция четко соответствовала общепризнанной мировой практике 
и рекомендациям Международного валютного фонда, в соответствии с которыми существует два основных принципа классификации государственного долга: первый — по валюте обязательства, когда внутренним признается долг, подлежащий оплате в национальной валюте, а внешний — в иностранной; и второй - по кредитору, когда внутренним признается долг, кредитором по которому является резидент соответствующего государства, а внешним - когда кредитором является нерезидент. Второй принцип классификации долга применяется преимущественно центральными банками, в частности при составлении платежного баланса.

Еще одним значительным изменением стало исчезновение из бюджетного законодательства классификации государственного долга, что также расходится с общепризнанной мировой практикой. Безусловно, предыдушая классификация видов внешнего и внутреннего долга, которая была в Федеральном законе «О бюджетной классификации» ${ }^{1}$, была далека от идеала, поскольку представляла собой два отдельных не связанных между собой перечня, в то же время полный отказ от классификации долга, по мнению многих практиков, не совсем оправдан ${ }^{2}$.

Следующим значительным изменением в статье 94 БК РФ стало указание в ней, что источником финансирования дефицита бюджета является именно разница (или, иначе говоря, сальдо) между привлечением из соответсвующего источника и его погашением, при этом детализация источников финансирования дефицита бюджета стала более подробной.

\footnotetext{
1 С3 РФ.1996.№ 34.Ст. 3040.

2 Мартьянов А.В. Управлением долгом в рамках изменений правового регулирования государственного долга // В сб.: Проблемы совершенствования бюджетной политики регионов и муниципалитетов: Материалы восьмой научно-практической конференции (16-18 июня 2008 г.) - Изд.во Петр ГУ, 2008. С. 134.
}

Новая редакция п. 1 статьи 110 может повлиять на прозрачность операций с источниками финансирования дефицита федерального бюджета, поскольку размеры привлечения и погашения по сути уже не утверждаются законом о федеральном бюджете, было бы более правильным отражать в Программме государственных заимствований не только разницу, но и отдельной строкой выделять привлечение и погашение из соответствующих источников.

Эффективное управление государственным долгом Российской Федерации и государственными финансовыми активами, направленное на сохранение достигнутой в последние годы высокой степени долговой устойчивости и поддержание высокого уровня кредитных рейтингов России инвестиционной категории.

Приоритетами долговой политики в области государственных внутренних заимствований Российской Федерации является финансирование дефицита федерального бюджета и развитие рынка государственных ценных бумаг. При этом ключевое значение имеет повышение ликвидности рыночной части государственного внутреннего долга, выраженного в государственных ценных бумагах, и сохранение оптимальной дюрации и доходности на рынке государственных ценных бумаг.

Долговая политика в сфере государственных внешних заимствований Российской Федерации заключается в обеспечении частичного финансирования дефицита федерального бюджета через осуществление регулярных заимствований в иностранной валюте путем размещения облигационных займов Российской Федерации в умеренных объемах на международных финансовых рынках капитала, поддержании репрезентативной кривой доходности по государственным долговым обязательствам в иностранной валюте, необходимой для формирования адекватных ориентиров для российских заемщиков. 
Повышению эффективности долговой политики в части осуществления заимствований на инвестиционные цели способствует применение программно-целевого метода в рамках бюджетирования, ориентированного на результат. Применение указанного метода создает возможности для контроля расходования бюджетных средств и оценки эффективности заемной и инвестиционной политики государства ${ }^{1}$.

С экономической точки зрения, государственный долг представляет собой задолженность государственных органов, как результат формирование дополнительных ресурсов государства, направленных на разрешение противоречий между экономическими и социальными потребностями общества на основе займов денежных средств у частных лиц, институтов, негосударственного сектора и иностранных государств. В статье 97, в соответствии с которой к государственному долгу относятся долговые обязательства, возникшие в результате принятия законодательных актов РФ об отнесении на государственный долг долговых обязательств третьих лиц, возникших до введения Бюджетного кодекса РФ, однако данная формулировка может иметь слишком широкое толкование, и может привести к росту объема государственного долга.

Согласно действующим нормам Бюджетного Кодекса РФ источники финансирования дефицита бюджета всегда взаимосвязаны с внутреними и внешними государственными заимствованиями. Бюджетный кодекс РФ является основным кодифицированным источником правового регулирования публичных долговых обязательств, в нем содержится раздел IV «Сбалансированность

\footnotetext{
1 Палюшок М.Н. Заимствования как фактор экономического развития региона // В сб. Проблемы совершенствования бюджетной политики регионов и муниципалитетов. Материалы восьмой научно-практической конференции (16-18 июня 2008 г.) - Изд. во Петр ГУ, 2008. С. 171.
}

бюджетов» который состоит из 6 глав, в том числе гл. 13 «Дефицит бюджета и источники его финансирования» и гл. 14 «Государственный и муниципальный долг», указанные главы взаимосвязаны между собой в них прослеживается связь по поводу сбалансированности бюджета (дефицита и профицита) и между государственным и муниципальным долгом, в связи с тем, что всегда должбы быть увязаны источники финансирования дефицита бюджета с внутреними и внешними государственными заимствованиями. Следует отметить, что в Бюджетном Кодексе РФ содержалась глава 12 «Профицит бюджета и порядок его использования», которая затем была исключена на основании Федерального закона от 5 августа 2000 г. № 116-Ф3², можно расценивать принятие бюджета с профицитом как нарушение принципа сбалансированности бюджета, или профицит бюджета можно рассматривать как источник погашения публичного долга. В связи с этим, экономисты-сторонники классического подхода придерживаются позиции, что бюджетный дефицит (профицит) и государственный долг допустимы как способ поддержания долгосрочной стабильности бюджета, при условии, что государство регулярно и в полном объеме выполняет свои расходные обязательства, не выходя при этом за пределы своего межвременного бюджетного ограничения ${ }^{3}$. Все эти меры, должны быть направлены на поддержание стабильности бюджета.

В пользу применения заемных инструментов выступает необходимость обеспечения баланса в уровне доходов и расходов бюджета: их использование предоставляет возможности приведения в соотвествие

\footnotetext{
2 О внесении изменений и дополнений вБюджетный кодекс Российской Федерации: Федеральный закон от 5 августа 2000 г. № 116 -Ф3 // СЗ РФ.— 2000.№ 32.-Ст. 3339; 2004. - 34.- Ст. 3535.

3 Золотарчук В.В. Макроэкономика: учебник / В. В. Золотарчук. М.: ИНФРА-М, 2011. С. 273.
} 
уровня принятых обязательств и уровня доходов бюджета. Подобная необходимость обуславливается возможностью появления временного несоответствия в уровне принятых обязательств и доходных поступлений в течении финансового года. Заимствования позволяют устранить этот разрыв и сохранить необходимый уровень предложенных государственных услуг.

Тем не менее заимствавания следует рассматривать, прежде всего, как инструмент среднесрочного и долгосрочного сбалансирования бюджета. Покрытие текущих расходов возможно в исключительных случаях в рамках финансового года - для покрытия дефицита, образующегося в результате кассовых разрывов.

Теория и практика осуществления заимствований и управления долговыми обязательствами в западноевропейских странах не дает однозначного ответа на вопрос о необходимости поддержания практики долевого финансирования со стороны органов власти. Очевидным является необходимость разделение заимствований по целям их осуществления и направлениям использования заемных ресурсов: на цели инвестиционного характера и на цели покрытия текущих расходов бюджета. «Золотое правило» сбалансированного бюджета предписывает осуществлять заимствования только для финансирования капитальных расходов, исключая возникнование долговых обязательств в результате осуществления заимствований с целью покрытия текущих расходов.

Классическая теория бюджетного федерализма допускает возможность и предпод- чительность финансирования инвестиционных проектов посредством осуществления заимствований в противовес финансированию за счет текущих расходов бюджета.

Государственные заимствования позволяют решать задачи нехватки средств при решении текущих задач исполнения бюджета и создают основу для перспективного развития, предоставляя возможности привлечения средств для достижения долгосрочных целей с учетом приоритетов инвестиционного развития.

Таким образом, политика заимствований и управления государственным долгом создает основы для решения стратегических и тактических задач социально экономического развития и выступает составной частью системы управления финансовыми ресурсами Российской Федерации. Эффективность финансовой системы государства находится в прямой зависимости от эффективности системы управления долговыми обязательствами.

Причиной возникновения государственного долга является проводимая государством политика, которая не обеспечивает сбалансированность доходов и расходов государства. Вместе с тем, в мире нет ни одного государства, которое в те или иные периоды своей истории не сталкивалось с проблемой государственного долга. Государственный долг является неотъемлимой частью большинства финансовых систем государств мира. Мировая практика свидетельствует о широком использовании государством заемной политики для финансирования расходов бюджета.

\section{Библиография}

1. Золотарчук В. В. Макроэкономика: учебник / В. В. Золотарчук. М.: ИНФРА-М, 2011. С. 273.

2. Мартьянов А.В. Управлением долгом в рамках изменений правового регулирования государственного долга // В сб.: Проблемы совершенствования бюджетной политики регионов и муниципалитетов: Материалы восьмой научно-практической конференции (16-18 июня 2008 г.) -Изд.во Петр ГУ, 2008. С. 134. 
3. Палюшок М.Н. Заимствования как фактор экономического развития региона // В сб. Проблемы совершенствования бюджетной политики регионов и муниципалитетов. Материалы восьмой научно-практической конференции (16-18 июня 2008 г.) -Изд.во Петр ГУ, 2008. С. 171

4. Покачалова Е. В. Правовые проблемы публичного долга в условиях дефицитной и профицитной бюджетной политики государства // Финансовое право и управление._-2014. - 1. C. 4-22. DOI: 10.7256/2310-0508.2014.1.9890.

5. Цареградская Ю. К. Управление государственным внешним долгом в современной России: подходы и тенденции развития // Актуальные проблемы российского права._-2013._-3.C. 276-281.

6. Е.В. Соловова. Выпуск государственных и муниципальных ценных бумаг как способ привлечения заемных средств в США. // Финансовое право и управление.-2013.—№ 1.C. 16-23. DOI: .10.7256/.2013.1.949

\section{References (transliterated)}

1. Zolotarchuk V. V. Makroekonomika: uchebnik/ V. V. Zolotarchuk. M.: INFRA-M, 2011. S. 273.

2. Mart'yanov A. V. Upravleniem dolgom v ramkakh izmenenii pravovogo regulirovaniya gosudarstvennogo dolga // V sb.: Problemy sovershenstvovaniya byudzhetnoi politiki regionov i munitsipalitetov: Materialy vos'moi nauchno-prakticheskoi konferentsii (16-18 iyunya 2008 g.) -Izd.vo Petr GU, 2008. S. 134.

3. Palyushok M.N. Zaimstvovaniya kak faktor ekonomicheskogo razvitiya regiona // V sb. Problemy sovershenstvovaniya byudzhetnoi politiki regionov i munitsipalitetov. Materialy vos'moi nauchnoprakticheskoi konferentsii (16-18 iyunya 2008 g.) -Izd.vo Petr GU, 2008. S. 171

4. Pokachalova E. V. Pravovye problemy publichnogo dolga v usloviyakh defitsitnoi i profitsitnoi byudzhetnoi politiki gosudarstva // Finansovoe pravo i upravlenie. - 2014. - 1. - C. 4-22. DOI: 10.7256/2310-0508.2014.1.9890.

5. Tsaregradskaya Yu.K. Upravlenie gosudarstvennym vneshnim dolgom v sovremennoi Rossii: podkhody i tendentsii razvitiya // Aktual'nye problemy rossiiskogo prava. - 2013. - 3. - C. 276-281.

6. E. V. Solovova. Vypusk gosudarstvennykh i munitsipal'nykh tsennykh bumag kak sposob privlecheniya zaemnykh sredstv v SShA. // Finansovoe pravo i upravlenie.-2013.—№ 1. - C. 16-23. DOI: .10.7256/.2013.1.949 